\title{
An Experimental Evaluation of Using Automotive HUDs to Reduce Driver Distraction While Answering Cell Phones
}

\author{
Christopher Nowakowski, Dana Friedman, and Paul Green \\ University of Michigan Transportation Research Institute (UMTRI) \\ Ann Arbor, Michigan 48109-2150 USA
}

\begin{abstract}
To examine strategies for reducing driver distraction while answering the phone, 24 participants answered calls while driving a simulator. Calls were answered using a center-console-mounted phone or one of several phone designs which utilized a HUD to display the caller ID and steering-wheel-mounted buttons to activate the phone. Driving workload was manipulated by varying the curve radius and by varying the timing of the call, either 1 second before or 5 seconds after the start of a curve.

The HUD-based phones resulted in response times that were 39 percent faster than the conventional center-console phone, and they resulted in up to 62 percent fewer line crossings. Additionally, when using the center-console phone, road curvature had a large influence on response times and driving performance; however, the HUD-based phone were less sensitive to increased road curvature or driving workload.
\end{abstract}

\section{INTRODUCTION}

A recent study by the National Highway Traffic Safety Administration [NHTSA] (Utter, 2001) estimated that 54 percent of drivers carry wireless phones, and an estimated 3 percent of all drivers (on average one-half million passenger vehicles) are actively engaged in a cell phone conversation at any given time during daylight hours. As the proliferation of cell phones continues, concerns regarding driver distraction and cell-phone-related crashes have been voiced, and the legislatures of several states have debated bills to restrict the use of cell phones while driving.

NHTSA (1997) estimated that between 8 and 15 percent of cell-phone-related crashes occurred while manipulating the phone. However, data from 1999 in Japan (Green, 2000) showed that cell-phone-related crashes were most associated with receiving a call (1077), followed by dialing (504), followed by talking (350), followed by other tasks (487), suggesting that at least 65 percent of the crashes involved manipulating the phone.

Research into cell-phone-related driver distraction has generally focused on two areas: conversation and phone manipulation. Several studies have focused on the cognitive demands of conversation while driving (McKnight and McKnight, 1993, and Alm and Nilsson, 1994). These types of studies have found little decrement in driving performance while conversing, and instead, they have relied on measures of situation awareness such as event detection tasks.

While conversation may impose cognitive demands, phone manipulation tasks impose cognitive, visual, and manual demands, often causing the driver's eyes and attention to be diverted from the road. Studies involving phone manipulation have generally been devoted to dialing tasks (such as Zwahlen, Adams, and Schwartz, 1988). There has been little research devoted to the phone answering task, which situation according to the Japanese data, may be the most distracting. This paper examines the following 3 questions in the context of answering the phone while driving:

1. How does the phone design (caller ID location) influence response time and driving performance?

2. Is a phone which uses a HUD less distracting when the auditory ring is turned off?

3. How does visual demand (driving workload) influence response time and driving performance?

\section{TEST PLAN}

\section{Test Participants}

Twenty-four licensed drivers participated in this experiment, 12 younger (20-30 years old, mean of 23 ) and 12 older (60-75 years old, mean of 67). Within each age bracket there were 6 men and 6 women. Participants were recruited via an advertisement in the local newspaper. All were paid $\$ 35$ for their participation, plus a potential $\$ 5$ bonus for good driving.

\section{Design}

Four performance measures, incoming call response time, standard deviation of lane position, line-crossing rate, and speed loss during the trial were examined using a repeated measures design. Driver age and sex were treated as between subject factors. Due to experimental constraints, phone design was treated as a single, 4-level, within subject factor. Road curvature (moderate and sharp) and call timing (before or during a curve) were also treated as within subject factors.

\section{Test Materials and Equipment}

The experiment was conducted using the UMTRI Driver Interface Research Simulator. The projection screen was $20 \mathrm{ft}$ $(6 \mathrm{~m})$ in front of the driver, effectively at optical infinity, with a 33 degrees horizontal by 23 degrees vertical field of view. Full details of the experiment can be found in Nowakowski, Friedman, and Green (2001).

The test roads had two, 12 -foot wide lanes $(3.7 \mathrm{~m})$, containing a mixture of straight sections and curves of 2 different radii (582 m and $194 \mathrm{~m}$ or 3 and 9 degrees of curvature, respectively). Both lanes were travelling in the same direction, simulating an expressway scenario driven at 45 $\mathrm{mph}(72 \mathrm{~km} / \mathrm{hr})$. The road geometries used were identical in width and radius to those in Tsimhoni and Green (1999). This study found that visual demand increased with linearly with the road curvature, and the peak demand for any given curvature occurred near the point of curvature but then stabilized at approximately 500 feet $(150 \mathrm{~m})$ into the curve. Thus, in the current experiment, the visual workload was manipulated both by increasing road curvature and by altering the timing of the call. The phone was set to ring either 65 feet $(20 \mathrm{~m})$, roughly 1 second before the curve, or 650 feet $(200 \mathrm{~m})$, roughly 5 seconds after the start of a curve after the visual demand had stabilized. With the inclusion of incoming calls during some straight sections of road for control, 5 unique levels of visual demand were examined. 
Three of the four phone designs used a HUD to display the caller ID (Table 1). The HUD image locations were measured in degrees down from horizontal and right of center, and they were selected to match several locations used in Tsimhoni, Watanabe, and Green (2000). The apparatus used to simulate the HUD consisted of an acrylic sheet (hung slightly in front of where the windshield would be) on which the images from a flat-panel LCD monitor placed on the dashboard were visible as reflections. The image focal distance was between 31.5 and 38.5 inches $(80$ and $100 \mathrm{~cm})$. Characters were monochrome green and of sufficient size to be quite legible.

Table 1. Designs Evaluated.

\begin{tabular}{|c|l|c|c|c|}
\hline \multirow{2}{*}{ Design } & \multirow{2}{*}{ Location } & \multicolumn{2}{|c|}{ Location (deg) } & \multirow{2}{*}{ Ring } \\
\cline { 3 - 4 } & & Down & Right & \\
\hline 1 & HUD center & 5.5 & 5.0 & yes \\
\hline 2 & HUD center & 5.5 & 5.0 & no \\
\hline 3 & HUD right & 5.5 & 15.0 & no \\
\hline 4 & Console & 25.0 & 24.0 & yes \\
\hline
\end{tabular}

Incoming calls were indicated by the appearance of a phone icon and the caller ID (Figure 1). After the call was answered, the HUD icon and caller ID changed to a call timer. Test participants initiated and ended calls by pressing the "Talk" and "End" buttons. For the HUD, these were mounted 3 inches $(7.5 \mathrm{~cm})$ from the right side of the steering wheel. For the touchscreen, the buttons were on the screen.
Incoming Caller ID

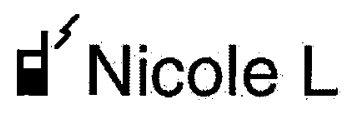

\section{di) 00:00:08}

Call Timer
Figure 1. HUD icons.

Design 4 was a simulation of a typical hands-free phone sitting in a cradle plugged into the $12 \mathrm{~V}$ outlet in the center console. This simulation was shown on a touchscreen in the center console, which was within a comfortable reach for most drivers. The simulated phone display was typical of most current cell phones and of sufficient size to be legible.

\section{Procedure}

After completing a consent form, a short biographical survey, and a vision test, the participants drove a practice road for 8 minutes, during which, baseline driving performance was recorded. Practice and training with each of the 4 phone designs was then given both while parked and while driving until the participants appeared reasonably comfortable with the answering task. Each of the 4 phone designs was examined in a separate block of 20 trials lasting about 18 minutes. Block order was counterbalanced across participants. Following the experiment, there was a brief post test survey, after which, the participants were thanked and paid.

Drivers were instructed to answer calls while driving safely and maintaining speed behind a lead vehicle. After detecting a call, the participant read the name of the caller from the caller ID and then pressed the talk button to answer the call. The participant then responded with, "Hello, [insert caller's name], this is [insert participant's name]. I can't talk right now. Can I call you back later?" The caller (a randomized recording) then replied with, "OK, give me a call later then. Bye." The participant ended the call with, "Bye," followed by pressing the end button on the phone. A typical call lasted between 8 and 10 seconds.

\section{RESULTS}

\section{Effect of Phone Design on Response Time}

The incoming-call response time represented the aggregate time to detect a call, read the caller ID, and press the "Talk" button. Driver age, $\mathrm{F}(1,20)=5.36, \mathrm{p}=.03$; phone design, $\mathrm{F}(3,60)=14.52, \mathrm{p}<.001$; and the age by phone design interaction, $F(3,60)=2.41, p=0.076$, were all significant for this measure of performance. A post hoc Tukey-Kramer test further revealed that only the response time for the centerconsole phone (mean 3.78 seconds, SD 2.44) was significantly different from the HUD phones. None of the 3 HUD-based cell phones were significantly different from each other (overall mean 2.32 seconds, SD 1.60). Overall, the mean response time for older drivers was 0.94 seconds greater than the mean for the younger drivers, but the older drivers required disproportionately longer than younger drivers, 1.77 seconds, to answer the center-console-based cell phone. (See Figure 2.)

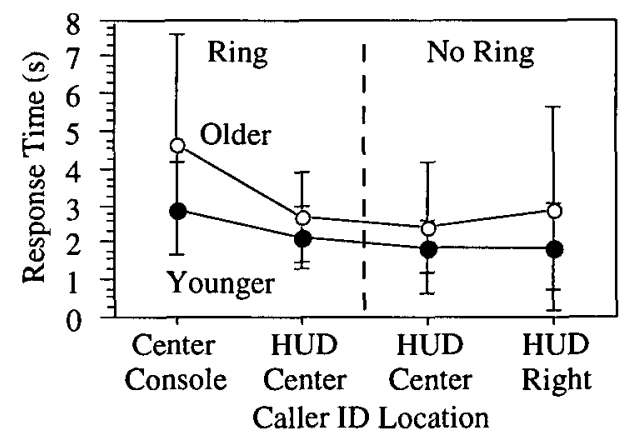

Figure 2. Effects of age and phone design on response time.

Although the analysis failed to show a significant difference between the 3 HUD-based phones, the mean response time for the HUD-based phone with a ring ( 2.43 seconds) was 0.3 seconds slower than the time to answer the same HUD-based phone without the ring ( 2.13 seconds). As shown in Figure 3, the response time distributions for the comparable ring and no ring conditions suggested that the presence of a ring may have influenced some of the participants. Further analysis indicated that 10 of the participants always answered before the end of the audible ring whether or not the ring was actually present. Nine of the participants rarely answered the phone during the audible ring when it was present, but typically answered the phone faster when the ring was absent. The remaining 5 participants showed no discernable trend.

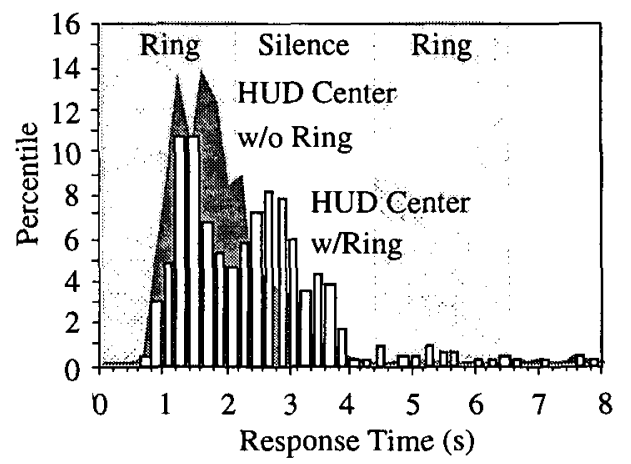

Figure 3. Effect of an audible ring on response time.

Although the presence of an auditory ring had an adverse effect on some of the test participants' response times, the 
absence of the auditory ring also produced a subtle effect on the distribution of response times. For the cell phone condition where the caller ID was in the center location on the HUD and a ring was provided, there were no response times recorded longer than 8 seconds. When the ring was not present (but the caller ID was still shown in the center HUD location), 8 trials (out of 480) were recorded with very long response times (between 8 and 21.1 seconds). When the ring was not present and the caller ID was shown on the far right HUD location, the number of long trials increased to 13 , and during 5 trials, the driver never saw the incoming call before it would have been routed to voicemail (24 seconds). All 5 of these trials occurred during left curves (where the driver was looking to the left while the caller ID appeared on the right).

\section{Effect of Phone Design on Driving Performance}

While longer response times may indicate increased task difficulty, they do not necessarily indicate a decrease in driving safety because drivers may sacrifice task performance for driving performance. Three measures were used to assess driving performance: (1) standard deviation of lane position, (2) line-crossing rate, and (3) speed loss during a trial.

Significant main effects were found for both driver age and phone design for the standard deviation of lane position (age effect $F(1,20)=16.37, p<.001$, and phone design effect $\mathrm{F}(4,80)=30.14, \mathrm{p}<.001)$ and for the line-crossing rate (age effect $F(1,20)=7.23, p<.001$, and phone design effect $\mathrm{F}(4,80)=11.12, \mathrm{p}<.001)$. Additionally, the interaction between age and phone design was significant for the standard deviation of lane position, $\mathrm{F}(4,80)=6.20, \mathrm{p}<.001$, and for the line-crossing rate, $F(4,80)=6.52, p<.001$. (See Figures 4 and 5.)

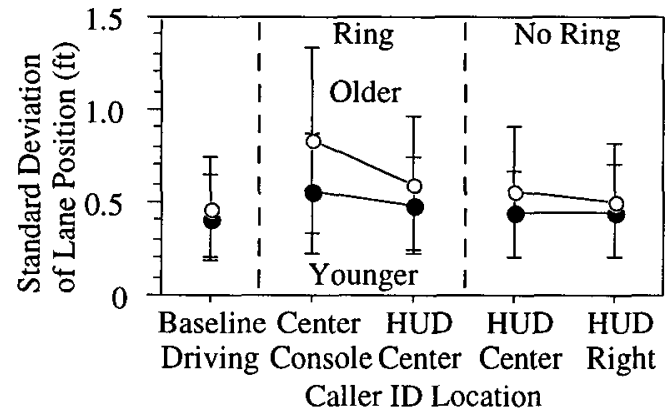

Figure 4. Effects of age and phone design on lane position.

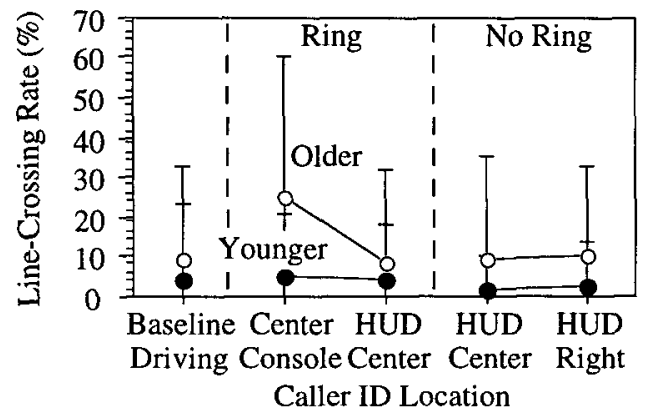

Figure 5. Effects of age and phone design on line crossings.

Overall, older drivers (mean standard deviation of lane position of 0.59 feet) were slightly more variable in keeping lane position than younger drivers ( 0.47 feet), and their driving resulted in a higher overall line-crossing rate (12.6 percent) than younger drivers ( 3.7 percent). However, the interaction between age and phone design showed that older drivers had significantly more difficulty keeping their lane position while answering the center-console-based cell phone. The mean standard deviation of lane position for older drivers increased from 0.47 feet during baseline driving to 0.83 feet while attempting to answer the center-console-based cell phone. Similarly, the line-crossing rate increased from 9.6 percent during baseline driving to 25 percent while answering the center-console-based cell phone. Remarkably, for the same group of drivers, there was almost no difference between baseline driving and answering any of the HUD-based phones for either the standard deviation of lane position (an increase from 0.47 to 0.55 feet) or the line-crossing rate (a decrease from 9.6 percent to 9.4 percent).

Younger drivers, on the other hand, showed little difference between any of the phone answering tasks and baseline driving for either lane keeping measure. The standard deviation of lane position for younger drivers only increased from 0.41 to 0.55 feet between the baseline driving and the center-console-based cell phone. Similarly, the line-crossing rate only increased from 4.6 percent during the baseline driving to 5.4 percent while answering the center-console cell phone. However, the line-crossing rate actually decreased to a mean of 2.8 percent while answering the HUD-based phones.

When overloaded, drivers also tend to slow down. Overall, speed loss occurred during 42.9 percent of the trials. An analysis of the speed loss during trials also showed that the phone condition was significant, $F(4,80)=4.22, p=.003$, and age was significant, $\mathrm{F}(1,20)=4.16, \mathrm{p}=.05$. Overall, baseline driving resulted in speed loss during 37.1 percent of the trials, and use of the center-console-based phone resulted in speed loss during 48.3 percent of the trials. Younger drivers showed no difference in speed loss between baseline driving and answering any of the phone designs. Older drivers, on the other hand, showed an increase in mean speed loss from $3.6 \mathrm{ft} / \mathrm{s}$ $(2.5 \mathrm{mph})$ during baseline driving to $5.4 \mathrm{ft} / \mathrm{s}(3.7 \mathrm{mph})$ while answering the center-console-based cell phone. (See Figure 6.) The speed loss strategy also appeared to be more common for older women as evident by the significant age by sex interaction, $F(1,20)=9.28, p=.006$, indicating that the mean speed loss for older women was $1.9 \mathrm{ft} / \mathrm{s}(1.3 \mathrm{mph})$ greater than that of older men.

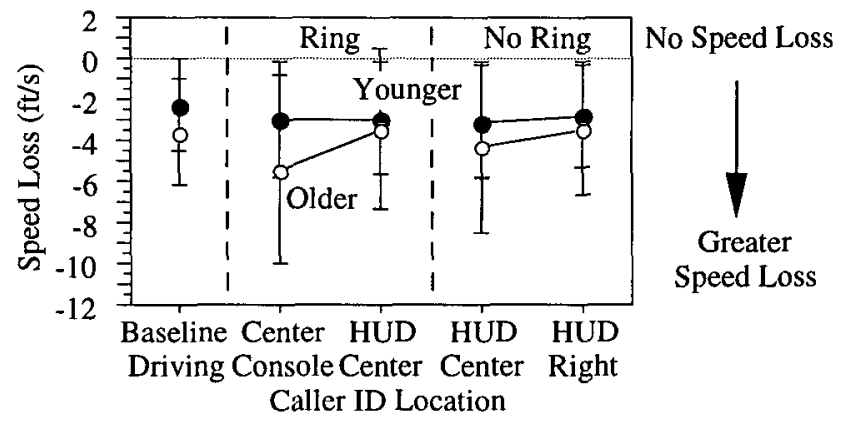

Figure 6. Effects of age and phone design on speed.

The Effect of Visual Demand on Response Time and Driving Performance

Two factors, road curvature and call timing, were manipulated to provide different levels of visual demand (driving workload) during the experiment. The main effect of 
road curvature was significant for the response time, $\mathrm{F}(1,20)=7.60, \mathrm{p}=.01$, the standard deviation of lane position, $\mathrm{F}(1,20)=140.75, \mathrm{p}<.001$, and the line-crossing rate, $F(1,20)=43.52, \mathrm{p}<.001$.

Overall, as the road curvature increased from 0 to 3 degrees, the response time increased from 2.31 to 2.53 seconds. Similarly, as the road curvature increased from 3 to 9 degrees of curvature, the response time increased from 2.53 to 3.02 seconds. However, the interaction between road curvature and caller ID location was also significant for the response time, $F(3,60)=6.32, p<.001$. As shown in Figure 7, the center-console cell phone resulted in disproportionately longer response times at higher driving workloads when compared to the HUD-based cell phones. Using the HUD-based cell phones, the mean response time only increased by 11 percent from 2.26 to 2.50 seconds between 3 and 9 degree curves. However, using the center-console-based cell phone, the mean response time increased by 37 percent from 3.35 to 4.59 seconds between 3 and 9 degree curves.

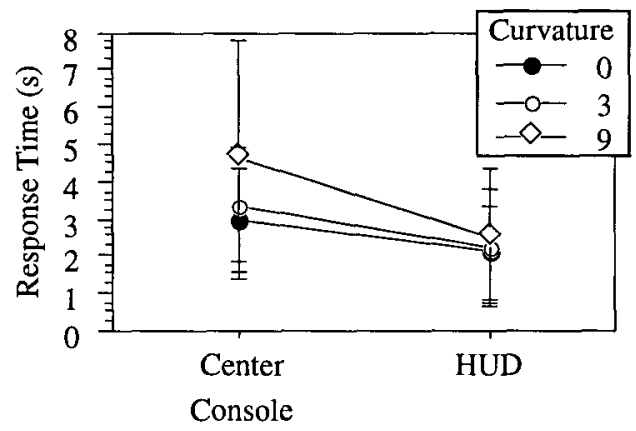

Figure 7. The interaction of curvature and phone design on response time.

Overall, as the road curvature increased from 0 to 3 degrees, both the standard deviation of lane position and the line-crossing rate increased (from 0.28 to 0.45 feet and from 2.1 to 4 percent, respectively). However, between 3 and 9 degrees of curvature, the standard deviation of lane position only increased from 0.45 to 0.74 feet while the lane crossing rate nearly quadrupled from 4 to 15.3 percent.

The interaction between road curvature and phone design was also significant for the line-crossing rate, $F(4,80)=2.99$, $\mathrm{p}=.02$. (See Figure 8.) When using the HUD-based cell phones, there was no difference in the line crossing rates between baseline driving and the answering task (averaging under 4 percent for 0 and 3 degree curves and between 12 and 14 percent for 9 degree curves). For the center-console-based cell phone, the line-crossing rate for 0 degree curves (straight roads) was 3.1 percent, which was equivalent to the baseline driving condition. However for 3 degree curves, the linecrossing rate increased to 9.1 percent, and for 9 degree curves, the line-crossing rate increased to 34.7 percent, both significantly higher than either the HUD-based cell phones or the comparable baseline driving conditions.

A second workload factor examined was the timing of the incoming calls, which occurred either 1 second before the start of a curve or 5 seconds after the start of a curve. The main effect of call timing was significant for the response time, $F(1,20)=6.20, p=.02$. The mean response time for calls taken during a curve was 0.17 seconds longer than the mean response time for calls taken just before the curve.
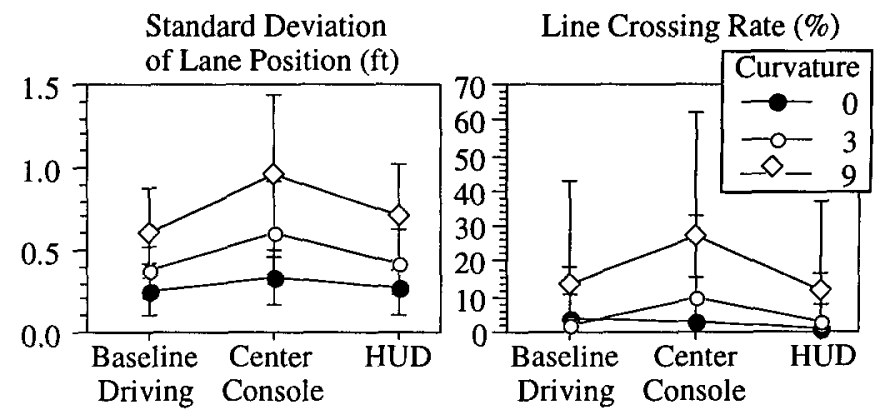

Figure 8. The interaction of road curvature and phone design on driving performance.

Although this might seem contrary to what would be expected, there was also a significant interaction between the call timing and the cell phone design, $\mathrm{F}(3,60)=5.51$, $\mathrm{p}=.002$. As shown in Figure 9, when there was no auditory ring, the response time to calls that came during the curve was greater than the response time to calls that came just before the curve. For the center HUD position, the response time increased from 2.02 seconds when the call came before the curve to 2.33 seconds when the call came during the curve. For the right HUD position, the response time increased from 2.21 seconds when the call came before the curve to 2.79 seconds when the call came during the curve. The increased response time when the calls came during a curve was likely due to an increase in HUD detection time, especially during left curves.

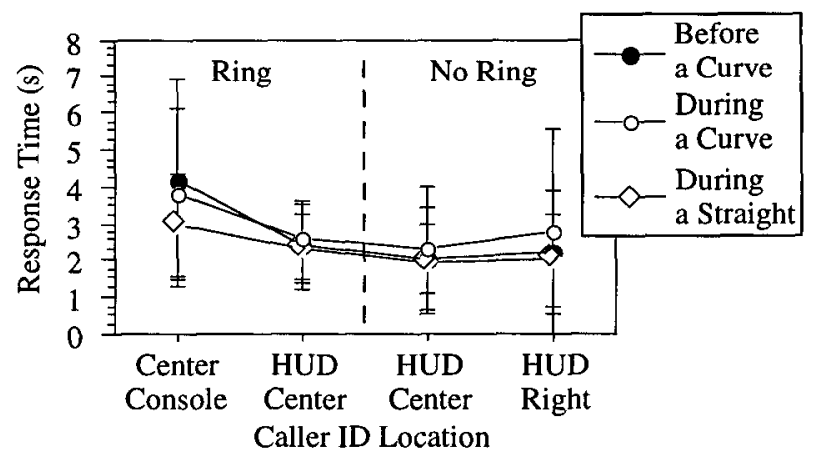

Figure 9. The interaction of call timing and phone design on response time.

Interestingly, there was a slight reversal of this trend when using the center-console-based cell phone. The mean response time for calls taken just before the curve was 4.15 seconds, which was slightly higher than the 3.80 seconds for calls taken during a curve. For the center HUD position with a ring, the call timing had no effect.

The main effect of call timing was significant for the standard deviation of lane position, $\mathrm{F}(1,20)=18.39, \mathrm{p}<.001$, indicating that lane variability when entering a curve $(0.65$ feet) was slightly greater than when driving in a constant curve ( 0.53 feet). However, no significant effects were found in the line-crossing rate for call timing.

For speed loss, the main effect of call timing, $F(1,20)=4.33, p=.05$, and the interaction between call timing and phone condition, $F(4,80)=4.51, \mathrm{p}=.002$, were significant. This simply indicated two things. First, speed loss was greater during the answering task than during baseline driving. Second, calls which came during a curve resulted in greater speed loss (a mean of $4.4 \mathrm{ft} / \mathrm{s}$ or $3 \mathrm{mph}$ on 45.8 percent 
of the trials).than calls which came just prior to the curve (a mean of $2.7 \mathrm{ft} / \mathrm{s}$ or $1.8 \mathrm{mph}$ on 36.5 percent of the trials).

\section{Hanging Up the Phone}

At the end of each trial, the test participants were required to end the call by pressing the "End" button, which required the same physical movement as answering the phone, but none of the urgency or surprise associated with the answering task. While the overall line-crossing rate during baseline driving was 7.1 percent, the overall line-crossing rate while pressing the end button after the call was only 5.6 percent. There were slight effects on the line crossing rate due to age (2.9 and 8.4 percent for young and older drivers) and curvature $(1,3.3$, and 10.4 percent for 0,3 , and 9 degree curves, respectively); but there were no differences observed due to phone design for any of the driving performance measures, suggesting that the manual component of the answering task had less influence on driver distraction than anticipated.

\section{Subjective Evaluation}

In ranking their location preferences, all but two of the subjects agreed that the caller ID should appear in the center HUD location. Using normalized stress ratings, participants felt that it was most stressful to answer a call when the caller ID was displayed on the center console. However, answering calls using any of the HUD-based phones was not much more stressful than driving alone. The conditions without an audible ring were rated as more stressful than those with an audible ring. Most test participants commented that without the ring, they had no way of knowing how long the phone icon had been displayed before they saw it, and thus, they felt more stress to answer the call quickly. As expected, stress increased as the degree of curvature increased, and participants felt that it was slightly more stressful to answer the calls which arrived 1 second before the beginning of a curve. There were no differences due to age or gender.

\section{KEY FINDINGS AND DESIGN IMPLICATIONS}

The first goal of this study was to ascertain whether or not a HUD could be effectively used to reduce driver distraction when answering a phone call. The mean response times favored the HUD-based phones by 1.46 seconds over the headdown, center-console location (with about 0.25 seconds of this difference due to button location according to estimates from SAE J2365). Additionally, the driving performance measures indicated that there was significantly more variability in lane keeping and more line crossings while answering the headdown, center-console-mounted phone as compared to the HUDbased phones.

Admittedly, by requiring the driver to read the caller ID before answering, the task favored the use of the HUD; and as found in Tsimhoni, Watanabe, and Green (2000), response times increased as HUD eccentricity increased. However, most current cell phones provide caller ID, and it is arguable that the habit of checking the caller ID before answering will not be so easily abandoned just because it may not be wise to do while driving. Providing caller ID may also reduce the number of calls taken while driving, should the driver decide not to take a call based on the caller ID.

This study also minimized the surprise of getting a phone call while driving. Although drivers did not know exactly when the phone would ring, they knew it would eventually ring. However, even using an optimally located hands-free phone and somewhat expecting a call, there were significant decreases in driving performance during the answering task. Given the variety of less optimal devices available, laws which simply require the use of a hands-free kit are short-sighted at best. However, this study does suggest that vehicle-integrated phones designs show some promise in helping to reduce the risk of cell-phone use while driving.

The second goal of this study examined the distraction potential of the ring. However, there was no indication that the presence or absence of a ring had any influence on driving performance. There was evidence that some drivers may have waited for the completion of a ring before answering. One direction for further research might examine varying the ring length and type to find out whether longer rings actually result in more distraction as measured by eyes-off-the-road time.

The third and final goal of this study was to examine the effects of momentary driving workload on cell phone use. As expected, increases in visual demand due to the curvature of the road produced both longer responses and worse driving. It was also expected that since the peak visual demand occurs just prior to entering a curve (Tsmhoni and Green, 1999), calls that occurred 1 second before the start of the curve should have resulted in delayed responses or worse driving performance. However, the results failed to show any change in phone answering behavior or any decrease in driving performance when the calls occurred just before a curve.

\section{ACKNOWLEDGMENTS}

This research, conducted at the University of Michigan Transportation Research Institute, was supported by Nissan Motor Company. The authors would like to thank Hiroshi Watanabe who served as the project liaison.

\section{REFERENCES}

Alm, H. and Nilsson, L. (1994). Changes in driver behavior as a function of handsfree mobile telephones. Accident Analysis and Prevention, 26(4), 441-451.

Green, P. (2000). Crashes induced by driver information systems and what can be done to reduce them (SAE paper 2000-01-C008). Convergence 2000 Conference Proceedings (SAE publication P-360, pp. 26-36). Warrendale, PA: Society of Automotive Engineers.

McKnight, A.J., \& McKnight, A.S. (1993). The effect of cellular phone use upon driver attention. Accident Analysis and Prevention, 25(3), 259-265.

National Highway Traffic Safety Administration. (1997). An Investigation of the Safety Implications of Wireless Communications in Vehicles. Available: http://www.nhtsa.dot.gov/people/injury/research/wireless/

Nowakowski, C., Friedman, D., and Green, P. (2001). Cell Phone Ring Suppression and HUD Caller ID: Effectiveness in Reducing Momentary Driver Distraction Under Varying Workload Levels (Technical Report UMTRI-2001-29). Ann Arbor, MI: The University of Michigan Transportation Research Institute.

Nowakowski, C. and Green, P. (1998). Map design: An on-the-road evaluation of the factors affecting the time to read electronic navigation displays (Technical Report UMTRI-98-4). Ann Arbor, MI: The University of Michigan Transportation Research Institute.

Society of Automotive Engineers (2002). Calculation of the Time to Complete In-Vehicle Navigation and Route Guidance Tasks (SAE Recommended Practice J2365). Warrendale, PA: Society of Automotive Engineers.

Tsimhoni, O., Watanabe, H., and Green, P. (2000). Display of Short Text Messages on Automotive HUDs: Effects of Workload and Location on Driving (Technical Report UMTRI-2000-13). Ann Arbor, MI, The University of Michigan Transportation Research Institute.

Tsimhoni, O. and Green, P. (1999). Visual Demand of Driving Curves Determined by Visual Occlusion. Paper presented at the Vision in Vehicles 8 Conference, Boston, MA.

Utter, D. (2001). Passenger vehicle driver cell phone use results from the fall 2000 national occupant protection use survey (DOT HS 809293 ) Washington, DC: National Highway Traffic Safety Administration.

Zwahlen, H., Adams, C., and Schwartz, P. (1988). Safety Aspects of Cellular Telephones in Automobiles (Paper 88058), 18th International Symposium on Automotive Technology and Automation. 